\section{Rent a theorist in Moscow}

\section{Washington}

SOVIET physicists, fearful of the impending economic 'anarchy' in their country, have dug deep into the capitalist bag of tricks to find a way to keep science alive in the USSR: they propose to rent themselves out.

For a price of between one-quarter and one-fifth of what research costs in the West, Soviet theoreticians at the Kurchatov research institute claim they can do the same or better calculations in Moscow. So they have set up an independent group of between 100 and 200 physicists, secured some Soviet government funding, and spread the word to their Western contacts that they are open for business for anyone who needs help with tough calculations.

Known as Mucatex, the group is headed by Kurchatov theoretical physics director Leonid Ponamarev and is said to include some of the best theoretical physicists in the world. Their speciality is muon-catalysed fusion, the technique of exchanging a heavy muon for the electron in a deuterium atom, which allows two deuterium atoms to get close enough to occasionally fuse and release large amounts of energy.

Although muon-catalysed fusion fell somewhat out of favour in the United States recently after being tarred by the 'cold fusion' brush, it is still an active field of research in dozens of laboratories worldwide. Supporters say it could play a critical role in future fusion technology by enhancing the performance of breeder reactors by a factor of two or three.

Western contacts for the Soviet researchers say their proposition is an attractive one for both sides. Researchers in the West can get time-consuming calculations done by some of the best theoreticians in the world at a cost far less than in the West. The Soviet government would get some hard cash and, more importantly, would be able to keep their top scientists from leaving the country. Organizers estimate that each deal would include about 20 per cent travel time for the Soviet researchers to visit the West to work with their sponsors.

"It took me 10 to 15 years to create a team that includes elementary-particle, quantumphysics, computer and accelerator physicists," says Ponamarev. "Now I am worrying that it will disappear in the coming chaos. To survive this group we need outside support." Ponamarev hopes that some of the time his researchers will spend in the West will be on high-performance computers. Computer resources are scarce in the Soviet Union, and Western nations are often reluctant to allow Soviet institutions direct access to their supercomputers, which are often used for classified research. "They'll probably do their thinking in Moscow and their number crunching in the West," says Birmingham University physicist John Davis, who has been in contact with the Soviet group.

Working under the umbrella of the World Laboratory (based in Lausanne, Switzerland), Mucatex has already established collaborations with the Paul Scherrer Institute in Zurich, the UK Rutherford Appleton Laboratory, the US Los Alamos Laboratory and institutions in Italy and Germany. The group is currently circulating a letter by Soviet Academy of Science Academician Eugenu Velikhov, seeking further collaborations. Western interest so far has been encouraging, says Ponamarev.

Christopher Anderson

\section{Human Frontiers gets extension}

\section{Japan}

JAPAN's unique Human Frontier Science Program (HFSP), which supports international research on the brain and molecular biology, seems set to continue until at least 1997. That is the most important decision to have arisen out of a HFSP board of trustees meeting earlier this month in Strasbourg, France.

The board of trustees, which consists of representatives from the seven Western summit nations (Japan, the United States, Canada, France, Italy, Germany and the United Kingdom) as well as the European Community and Switzerland, unanimously agreed at the closed meeting on 5-6 June to continue the programme for another five years after the initial three-year phase ends in March 1992. At the end of the next fiveyear phase, Frontiers will undergo major review with the possibility of extension for another five years, Japanese government officials say.

A confidential report from the meeting, which is being circulated among various ministries in Tokyo, also says that the board expects financial contributions from other member nations apart from Japan to increase "until an equal match is achieved". At present, Japan is providing about 80 per cent of the programme's annual budget of approximately $\$ 30$ million.

A budget proposal for fiscal 1991 presented at the meeting reveals that Germany has agreed to make a substantial "in-kind" contribution to the programme, paying more than $\$ 1$ million to cover the salaries of HFSP fellowship awardees. This will make Germany the third largest contributor after Japan and France.

The proposed budget also includes an in-kind contribution from the United States of about $\$ 40,000$ to support the salary of one HFSP fellow at the US National Institutes of Health. This confirms earlier reports that the institutes are prepared to make a tiny but politically significant contribution to the programme (Nature 350, 97; 1991). This leaves the United Kingdom as the only member state that is not making any financial contribution to Frontiers.

Japanese government officials say they are generally pleased with the outcome of the Strasbourg meeting and with the growing financial support for the programme from other member nations, but there is one matter that irritates them. France is putting a 24 per cent tax on interest earned from HFSP funds deposited in France, where the HFSP organization is based. This tax nets the French government nearly $\$ 750,000$, or almost half of the country's $\$ 1.5$-million annual contribution to Frontiers. Japan and other member nations have appealed to France to exempt the programme from tax, but so far to no avail.

David Swinbanks 